\title{
Building Political Risk Management Skills in the Middle East
}

\author{
Tim J. Rogmans, Zayed University, United Arab Emirates
}

GLOBAL MARKETS ARE INCREASINGLY characterized by political risk $^{1}$ and uncertainty, nowhere more so than in the Middle East North Africa (MENA) region. Since 2010, governments have been overturned in Tunisia, Libya, Egypt, and Yemen, while Syria, Lebanon, Iraq, and Bahrain are also in turmoil. Meanwhile, the Israeli-Palestinian conflict and the standoff over Iran's nuclear program are far from settled. These developments have a large impact on business throughout the region, as old trading routes become unviable and investors and tourists seek safe havens.

In this environment, are there are any good reasons for companies to invest in the region? What are the entry methods and ownership modes that successful companies use when faced with political turmoil? A number of multinational companies are aware that there are fundamental strengths in the economies in the region that are likely to endure and are taking action to capitalize on the opportunities. These companies don't accept political risk as a showstopper for their international development but instead are building their own in-house skills to manage political risk.

\section{The Opportunity}

Most economies in the MENA region have suffered as a result of the regional political turmoil and the global economic slowdown. Foreign direct investment flows into the region have fallen by over 50 percent from a high of US\$114 billion in 2008 to US\$38 billion in 2012 (UNCTAD, 2009 , 2013). Tourists are shying away Egypt, Tunisia, Syria, and Lebanon, and intra-regional trade has stagnated. How do multinational companies survive and prosper in such a challenging environment? First, within any turbulent region there are opportunities in specific markets that continue to thrive. For example, tourism in the UAE has benefited from traffic diverted from higher risk locations. Construction in Saudi Arabia and Qatar continues unabated on the back of high oil prices. The private education sector throughout the region is maintaining its growth as the population expands, and parents are keen to invest in their children's future. Even within an apparently high-risk country such as Iraq, the Kurdistan region is undergoing rapid economic development. In addition to these specific areas of opportunity, the overall region also offers tremendous potential in the medium term, based on four fundamental drivers of economic growth.

\section{Demographics}

Much of the MENA growth story is about demographics. As the Western world ages, the population in the MENA region is projected to grow by 81 percent over the next 40 years, from 217 million people today to 392 million in 2050 (Population Reference Bureau, 2010). A relatively high proportion of the population will be of working age. In parallel, the increasing labor participation of women, higher education levels, and continuing urbanization will put additional pressure on the job creation capabilities of regional economies. Although these trends may lead to social pressures, the impact of demographic trends on economic growth is positive. Markets for anything from consumer goods to healthcare to infrastructure will be supported by these demographic developments.

\section{Improving Business Regulation}

Despite political instability, the regulatory environment for doing business in the region is improving steadily, as symbolized by Saudi Arabia's entry to theWTO in 2005 and as evidenced by the improvement of Arab countries in the various business regulation rankings. This is particularly the case for the six GCC countries (Bahrain, Kuwait, Kuwait, Oman, Saudi Arabia, United Arab Emirates), which all feature among the top 70 countries in the World Bank's "Doing Business" ranking, with Saudi Arabia at 12 ${ }^{\text {th }}$ place on the list in 2012 (World Bank, 2012).

\section{Continuing Energy Wealth}

Although the energy-rich countries in the region are making serious attempts to diversify their economies beyond oil and gas, the reality is that the region's energy resources are not going to run out any time soon. At current production rates, Iraq, Kuwait, Saudi Arabia, and the UAE all have more than 70 years' worth of oil reserves, while Qatar has more than 100 years of gas supply (BP, 2011). These massive resource endowments underpin government budgets and trade balances for decades to come and thereby support continuing outlays on infrastructure, health, education, industry, and housing. 


\section{Turning East}

The MENA region is strategically located between East and West, allowing airlines and ports to position themselves as global hubs. Hence the region benefits from growth in trade between Asia and commodity rich Africa and Latin America. Bilateral trade and investment links between the MENA region and Asia have grown rapidly, especially between the GCC region and China and India. This development has been referred to as "The New Silk Road," illustrating a revival of commercial links that have existed for centuries (Simpfendorfer, 2009).

Although these growth drivers are specific to the MENA region, they have relevance to many emerging markets that are experiencing population growth, significant natural resource wealth, and increasing pressure to improve business regulation in order to boost economic growth and facilitate job creation.

\section{Political Risk Management}

How do multinational companies plan for success in this potentially promising but turbulent environment? In-depth interviews with senior managers of companies from Europe, the US, and Japan operating in a range of industry sectors across the MENA region have pointed to five key practices that are consistently used by successful international direct investors. These practices all point toward the importance of the in-house development of the skills required to manage political risk and to deal with local authorities. Rather than subcontracting these activities to local partners, multinationals that commit to the region see political risk management skills as a source of competitive advantage.

\section{Accept and Manage Political Risk}

Experienced foreign investors have learned that political risk is an inherent characteristic of the MENA region and of emerging markets in general, and it is unlikely to go away anytime soon. Therefore, rather than waiting for some indefinite political endgame to materialize, these companies analyze the specific political and regulatory risks they face in various markets and adapt their approach to suit the circumstances. If a market is sufficiently attractive, political risk is rarely a reason not to invest, unless the physical safety of the company's personnel is at stake.

Identifying political risks goes beyond the consideration of ranking tables of the business environment or competiveness of countries. These rankings provide a useful first glimpse of a country, but they have now received so much attention in the press that The Economist concluded that some countries are now "gaming the system," i.e., introducing reforms that elevate a country in the ranking without really improving the business environment in a significant way (The Economist, 2010). That is why some companies maintain their own risk scoring systems based on their own perception of relevant risk types. Although this is not always necessary, it has the benefit of clarifying the risks that really matter to the specific investment projects under consideration.

\section{Avoid Political Partnerships}

Companies without direct experience managing in a culturally distant country are often tempted to enter into local partnerships. Especially in countries where the regulatory environment is unknown to the investor or lacks transparency, it may appear attractive to tie up with parties that have close connections to the government. Such reasoning is in line with the view among business scholars that it makes sense to combine capabilities between firms. A foreign firm brings a particular product or service to a market, while a local firm delivers expertise on how to deal with the authorities. In practice, these politically driven partnerships often fail to stand the test of time. In today's turbulent environment, either the local partner may fall out of favor with the host country government or the government itself may change, making connections with the old regime worthless or even detrimental to a business. In any case, such connections are often only useful during the initial phase of an investment project and become less relevant as a new venture establishes its own roots.

The US Foreign Corrupt Practices Act (FCPA) has given additional impetus to this idea, stipulating that political partnerships are not allowed and that only the foreign investor can speak on its own behalf to the host country authorities. The law prohibits unlawful payments to foreign officials, either directly or made through intermediaries, joint ventures, or agents. Knowledge that an improper payment may reach a foreign official is already a breach of the Act. This legislation applies not only to companies of US origin but to the foreign subsidiaries of all companies that operate in the US. The UK Bribery Act operates in a similar way for UK companies.

The most successful foreign investors in the Middle East have formed partnerships only when there are true complementary business capabilities between the parties. In such cases, the local partner may bring specialized knowledge or assets related to the actual business being undertaken. Meanwhile, the foreign investor builds up its own knowledge of a country's political risk and regulatory framework. If additional expertise is needed to speed up the learning process or to make contacts with the authorities it can be obtained through the use of consultants, the recruitment of local staff and the support of the company's home country consulate. None of these methods of dealing with local authorities require the sharing of equity between the foreign investor and a local partner.

Of course, some jurisdictions don't allow for full foreign ownership in all or some sectors of the economy. Even in such cases, when a joint venture structure is a legal requirement, foreign companies should partner with local companies that bring more to the table than a local presence and political connections. The so-called "silent partnerships," whereby a local partner controls the venture on paper but in practice only receives a fee for providing contacts and administrative services, work well while they last. As soon as a conflict of any kind breaks out, the courts will only consider what is written in the contracts between the parties, with the usual result that the foreign minority shareholder loses out. Better options for foreign investors are to maintain full 
ownership, operate through franchisees which it can terminate when the franchisee does not fulfill its contractual commitments or to build a true joint venture with both parties contributing to the success of the operation.

\section{Maintain a Flexible Ownership Structure}

There are generally two reasons why a company may want to change its ownership arrangements in a foreign market: as a result of experience that has been built up or in the context of changing external circumstances, principally legislative changes that make more ownership modes available to the investor.

The internationalization process model of the firm (Johanson \& Vahlne, 1977) suggests that firms gradually increase their commitment in foreign markets as they accumulate experience of working in a country. In this model, firms start their expansion into a foreign market by exporting or through franchising. As they gain more knowledge, the perceived risk of operating in the country diminishes, and firms look to switch to higher equity operation modes such as a joint venture or a wholly owned subsidiary. In addition to the accumulation of experience, changing regulations also change the ownership preferences of foreign investors. As countries increasingly compete to attract FDI, the opportunities for full foreign ownership are steadily expanding across the region. For example, in the UAE the concept of free zones has expanded steadily, enabling foreign investors to maintain full ownership in a variety of industries, as long as they remain within the operating rules of the free zone. In other countries, such as Bahrain, Qatar, and Saudi Arabia, full foreign ownership has become an option in several industry sectors, even in onshore locations. As these legislative changes occur, companies that entered into joint venture arrangements only for the purpose of dealing with licensing requirements are looking for a way out.

In practice, many companies find it difficult to change their ownership structure in the face of these changing circumstances. If an existing local partner would lose out from exiting an agreement, there are various ways it can make life difficult for the foreign investor. A bitter local partner can negatively impact a foreign investor's reputation among the authorities or with customers and may exploit intellectual property that has been contributed to the venture by the foreign company. If a conflict with a local partner needs to go to arbitration, the party with the majority ownership in the venture (i.e., the local partner) will typically have the upper hand. In addition, changing ownership structure will often also require a company to move offices (for example to a free zone) and to transfer the visas of staff. All these considerations lead to high switching costs.

The need to switch operation modes can be avoided by partnering with companies that bring more to the table than just a local presence. In this case, even if changing regulations make full foreign ownership easier, there will be a business rationale for staying together. On the other hand, if the partnership is primarily a way to deal with licensing requirements, the parties need to make it clear that this is the case and should agree when and how the partnership is terminated. In this way, surprises are avoided and parties can move on without regret. The challenge in all this is to make sure that any legal documentation accurately reflects the relationship that the partners actually intend to have. As everywhere, when there is litigation, it is the signed contract between the parties that forms the basis for arbitration, rather than any unrecorded conversations that the parties may have had. This applies even in cultures where business is said to be relationship based.

\section{Hire Local Staff}

There are both demand and supply considerations that make it imperative for companies operating in the Middle East, particularly the Gulf region, to hire more local staff than they have done up to now. With the rapid growth of the local labor force, improvement in education levels in the region, and the fact that government jobs are increasingly hard to obtain, hiring local staff is now easier than before. Hiring local staff is often a cheaper way of obtaining local expertise and potential business contacts than using consultants. The recruitment of local staff also provides more flexibility than a joint venture arrangement. If an employee does not perform, there are ways of dealing with the situation. If a joint venture partner does not live up to expectations, it's more complicated.

Western universities now graduate large numbers of Arabic speakers who can be effective managers for companies operating outside or inside the Middle East. In many successful cases, Arab graduates are recruited into a company in the US or Europe where they start their careers. After several years in the company's home market operations, they return to their country of origin at a senior level and act as an effective bridge between the country operation and the rest of the company. Local universities also increasingly turn out highly qualified bilingual graduates in a variety of disciplines.

The benefit of hiring local staff manifests itself at all levels, from junior staff needing to speak Arabic with customers and suppliers, to senior management and country level board members needing to network with senior clients and authorities. In the near future, companies will probably not have a choice about recruiting local employees as Gulf governments are becoming more serious about sanctions and incentives to encourage the localization of the workforce. It is much better to be proactive about hiring local staff and see it as a business opportunity rather than as a cost of doing business. Usually, lack of experience and negative reports from other investors make companies underestimate the local talent pool. Nearly every company that has made a serious effort in growing its local workforce has done very well out of it.

\section{Stay the Course}

Once a company has entered a market, its fortunes are affected by internal and external factors, including market conditions and political developments. Doing business in emerging markets requires flexibility 
and patience. Investments that look like they are not progressing for years may suddenly pay off and the fact of having been on the ground continuously can contribute to a company's chances of success.

A foreign investor may scale its investment up or down depending on the circumstances. However, if a company is considering exiting a market completely, it needs to realize that it will be extremely difficult to make a successful re-entry. Regulatory authorities and customers tend to have a good memory of who stuck around during difficult time and will reward loyal multinationals. Citibank learned this lesson in Saudi Arabia, where it closed its offices in 2004. When it subsequently wanted to re-enter the market, it found that the regulatory authority had "temporarily halted"2 the issuing of new licenses. Therefore, even if a company's commitment to a market decreases, it should keep a minimum legal and physical presence if it is to maximize its chances of success when circumstances become more favorable.

By applying the five practices of investing in countries with political risk, multinational companies can grow with confidence in markets that have great promise over the medium term and at the same time manage their downside risk in the face of political volatility. Companies investing in political risk management skills are able to grow and maintain a competitive advantage over players who see the management of political risk as an issue to be outsourced to local partners.

\section{Endnotes}

1. The mostly widely used definition of political risk is by F.R. Root (2010: 130-132), who states that political risk arises from "uncertainty over the continuation of present political conditions and government policies in the foreign host country that are critical to the profitability of an actual or proposed equity/contractual business arrangement." Root distinguishes four main types of political risks to be evaluated by investors: general instability, expropriation risk, operations risk, and transfer risk.

2. A year later after exiting Saudi Arabia, Mohammad Al Shroogi, the Citibank Middle East managing director, called the exit a "mistake" and said the bank was reapplying for a license to operate. The central bank, the Saudi Arabian Monetary Agency (SAMA), "has temporarily halted the issuance of new bank licenses in order to evaluate the many licenses issued so far," he said. As reported by Arabian Business "Bringing it all back home" (2010).

\section{References}

BP. 2011. BP statistical review of world energy. http://www.bp.com/ assets/bp_internet/globalbp/globalbp_uk_english/reports_ and_publications/statistical_energy_review_2011/STAGING/ local_assets/pdf/statistical_review_of_world_energy_full_ report_2011.pdf. Accessed 15 February 2013.

The Economist. 2010. Snipping off the shackles. 4 November 2010. http://www.economist.com/node/17419783. Accessed 15 February 2013.
Johanson, J., \& Vahlne, J. E. 1977. The internationalization process of the firm - A model of knowledge development and increasing foreign market commitments. Journal of International Business Studies, 8(1): 23-31.

Population Reference Bureau. 2010. World population datasheet. http:// www.prb.org/Publications/Datasheets/2010/2010wpds.aspx. Accessed 15 February 2013.

Root, F. R. 1994. Entry strategies for international markets. San Fransisco: Josey-Bass.

Simpfendorfer, B. 2009. The new silk road - How a rising Arab world is turning away from the West and rediscovering China. New York: Palgrave MacMillan.

United Nations Conference on Trade and Development (UNCTAD). 2009. World investment report. http://unctad.org/en/docs/ wir2009_en.pdf. Accessed 15 February 2013.

United Nations Conference on Trade and Development (UNCTAD). 2013. Global investment trends monitor, No. 11. http://unctad.org/ en/PublicationsLibrary/webdiaeia2013d1_en.pdf. Accessed 15 February 2013.

World Bank. 2012. Doing business in a more transparent world. http:// www.doingbusiness.org/reports/global-reports/doingbusiness-2012. Accessed 15 February 2013.

Tim Rogmans is an Assistant Professor at the College of Business at Zayed University in Dubai, United Arab Emirates, previously worked in Europe as a strategy consultant for LEK Consulting, Gemini Consulting, and as a senior manager with Atradius Credit Insurance. In the Middle East, he has worked as Department Chairman at the Rafik Hariri University and as Director of Zayed University's Executive Education activity. His research is in the areas of Foreign Direct Investment, entry strategies and mergers \& acquisitions, with a focus on the Middle East region. He is the author of the book The Emerging Markets of the Middle East; Strategies for Entry and Growth. Tim is a board member of the AIB - MENA Chapter. He holds a Bachelors degree from the London School of Economics, an MBA from INSEAD and a PhD from Nyenrode University. 